\title{
Human papillomavirus and survival of patients with oropharyngeal cancer.
}

\author{
K Kian Ang \\ University of Texas M.D. Anderson Cancer Center \\ Jonathan Harris \\ Radiation Therapy Oncology Group Statistical Center, Philadelphia \\ Richard Wheeler \\ Huntsman Cancer Institute \\ Randal Weber

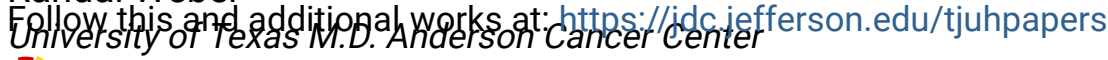 \\ Part of the Dermatology Commons, Infectious Disease Commons, and the Medical Cell Biology
David I Rosenthal \\ University of Texas M.D. Anderson Cancer Center \\ Let us know how access to this document benefits you
}

\section{See next page for additional authors}

Recommended Citation

Ang, K Kian; Harris, Jonathan; Wheeler, Richard; Weber, Randal; Rosenthal, David I; Nguyen-Tân, Phuc Felix; Westra, William H; Chung, Christine H; Jordan, Richard C; Lu, Charles; Kim, Harold; Axelrod, MD, Rita S.; Silverman, C Craig; Redmond, Kevin P; and Gillison, Maura L, "Human papillomavirus and survival of patients with oropharyngeal cancer." (2010). Jefferson Hospital Staff Papers and Presentations. Paper 8.

https://jdc.jefferson.edu/tjuhpapers/8

This Article is brought to you for free and open access by the Jefferson Digital Commons. The Jefferson Digital Commons is a service of Thomas Jefferson University's Center for Teaching and Learning (CTL). The Commons is a showcase for Jefferson books and journals, peer-reviewed scholarly publications, unique historical collections from the University archives, and teaching tools. The Jefferson Digital Commons allows researchers and interested readers anywhere in the world to learn about and keep up to date with Jefferson scholarship. This article has been accepted for inclusion in Jefferson Hospital Staff Papers and Presentations by an authorized administrator of the Jefferson Digital Commons. For more information, please contact: JeffersonDigitalCommons@jefferson.edu. 


\section{Authors}

K Kian Ang; Jonathan Harris; Richard Wheeler; Randal Weber; David I Rosenthal; Phuc Felix Nguyen-Tân; William H Westra; Christine H Chung; Richard C Jordan; Charles Lu; Harold Kim; Rita S. Axelrod, MD; C Craig Silverman; Kevin P Redmond; and Maura L Gillison 


\title{
Human Papillomavirus and Survival of Patients with Oropharyngeal Cancer
}

\author{
K. Kian Ang, M.D., Ph.D., Jonathan Harris, M.S., Richard Wheeler, M.D., \\ Randal Weber, M.D., David I. Rosenthal, M.D., Phuc Felix Nguyen-Tân, M.D., \\ William H. Westra, M.D., Christine H. Chung, M.D., \\ Richard C. Jordan, D.D.S., Ph.D., Charles Lu, M.D., Harold Kim, M.D., \\ Rita Axelrod, M.D., C. Craig Silverman, M.D., Kevin P. Redmond, M.D., \\ and Maura L. Gillison, M.D., Ph.D.
}

ABSTRACT

From the University of Texas M.D. Anderson Cancer Center, Houston (K.K.A., R. Weber, D.I.R., C.L.); Radiation Therapy Oncology Group Statistical Center (J.H.) and Thomas Jefferson University Hospital (R.A.) - both in Philadelphia; Huntsman Cancer Institute, Salt Lake City (R. Wheeler); Centre Hospitalier de l'Université de Montréal, Montreal (P.F.N.-T.); Johns Hopkins University, Baltimore (W.H.W.); Vanderbilt University School of Medicine, Nashville (C.H.C.); University of Louisville, Louisville, KY (C.C.S.); University of California at San Francisco, San Francisco (R.C.J.); Wayne State University Medical Center, Detroit (H.K.); University of Cincinnati College of Medicine, Cincinnati (K.P.R.); and the Ohio State University Comprehensive Cancer Center, Columbus (M.L.G.). Address reprint requests to $D$ r. Gillison at Ohio State University, 420 W. 12th Ave.,

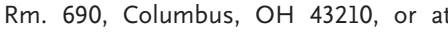
maura.gillison@osumc.edu.

This article (10.1056/NEJMoa0912217) was published on June 7, 2010, at NEJM.org.

N Engl J Med 2010;363:24-35.

Copyright (c) 2010 Massachusetts Medical Society.

\section{BACKGROUND}

Oropharyngeal squamous-cell carcinomas caused by human papillomavirus (HPV) are associated with favorable survival, but the independent prognostic significance of tumor HPV status remains unknown.

\section{METHODS}

We performed a retrospective analysis of the association between tumor HPV status and survival among patients with stage III or IV oropharyngeal squamous-cell carcinoma who were enrolled in a randomized trial comparing accelerated-fractionation radiotherapy (with acceleration by means of concomitant boost radiotherapy) with standard-fractionation radiotherapy, each combined with cisplatin therapy, in patients with squamous-cell carcinoma of the head and neck. Proportional-hazards models were used to compare the risk of death among patients with HPV-positive cancer and those with HPV-negative cancer.

\section{RESULTS}

The median follow-up period was 4.8 years. The 3-year rate of overall survival was similar in the group receiving accelerated-fractionation radiotherapy and the group receiving standard-fractionation radiotherapy $(70.3 \%$ vs. $64.3 \% ; \mathrm{P}=0.18$; hazard ratio for death with accelerated-fractionation radiotherapy, $0.90 ; 95 \%$ confidence interval [CI], 0.72 to 1.13), as were the rates of high-grade acute and late toxic events. A total of $63.8 \%$ of patients with oropharyngeal cancer (206 of 323) had HPV-positive tumors; these patients had better 3-year rates of overall survival $(82.4 \%$, vs. $57.1 \%$ among patients with HPV-negative tumors; $\mathrm{P}<0.001$ by the log-rank test) and, after adjustment for age, race, tumor and nodal stage, tobacco exposure, and treatment assignment, had a $58 \%$ reduction in the risk of death (hazard ratio, $0.42 ; 95 \% \mathrm{CI}$, 0.27 to 0.66 ). The risk of death significantly increased with each additional packyear of tobacco smoking. Using recursive-partitioning analysis, we classified our patients as having a low, intermediate, or high risk of death on the basis of four factors: HPV status, pack-years of tobacco smoking, tumor stage, and nodal stage.

\section{CONCLUSIONS}

Tumor HPV status is a strong and independent prognostic factor for survival among patients with oropharyngeal cancer. (ClinicalTrials.gov number, NCT00047008.) 
T HE MAJORITY OF PATIENTS ENROLLED IN therapeutic trials for squamous-cell carcinoma of the head and neck have oropharyngeal squamous-cell carcinoma, which in a subgroup of these patients is caused by infection with human papillomavirus (HPV). ${ }^{1}$ This subgroup is defined by the presence of high-risk types of HPV in tumor cells, predominantly HPV type 16 (HPV16). Expression of viral E6 and E7 oncoproteins that inactivate the tumor-suppressor proteins p53 and the retinoblastoma protein ( $\mathrm{pRb}$ ), respectively, is necessary for malignant behavior of these tumors. $^{2}$

Several retrospective case series have shown that among patients with oropharyngeal squamous-cell carcinoma, patients with HPV-positive tumors have a better prognosis than patients with HPV-negative tumors. ${ }^{3}$ Similar findings were reported in a prospective analysis of data from a clinical trial. ${ }^{4}$ Because of the small sample, however, other favorable prognostic factors associated with tumor HPV status (e.g., early tumor stage or young age) could not be ruled out as an explanation for the observed difference in survival.

We sought to evaluate the effect of tumor HPV status on survival in patients with oropharyngeal squamous-cell carcinoma who were enrolled in a clinical trial of sufficient size to account for potentially confounding factors, including smoking status. Our analysis was performed within a randomized clinical trial conducted by the Radiation Therapy Oncology Group (RTOG; the RTOG 0129 study). Meta-analyses of clinical trials for patients with locally advanced squamous-cell carcinoma of the head and neck have shown that both accelerated-fractionation radiotherapy 5 and concurrent cisplatin-based chemotherapy improved survival as compared with standard-fractionation radiotherapy alone. ${ }^{6}$ The RTOG 0129 study addressed the question of whether accelerated-fractionation radiotherapy is superior to standard-fractionation radiotherapy when each radiotherapy regimen is combined with concurrent cisplatin therapy. We report the results of this trial with an emphasis on the effect of tumor HPV status on survival among patients with oropharyngeal squamous-cell carcinoma.

\section{METHODS}

\section{STUDY PROTOCOL}

The RTOG 0129 study was registered with the National Cancer Institute and approved by the in- stitutional review boards at the participating centers. All patients provided written informed consent. The authors attest to the fidelity of the article to the full protocol and statistical-analysis plan.

Eligibility criteria were the presence of untreated, pathologically confirmed, stage III or IV squamous-cell carcinoma of the oral cavity, oropharynx, hypopharynx, or larynx without distant metastases $(\mathrm{M} 0)^{7}$; Zubrod's performance status score of 0 or 1 (asymptomatic or symptomatic but ambulatory, respectively) ${ }^{8}$; age of 18 years or older; and adequate bone marrow, hepatic, and renal function. Lifetime tobacco exposure was determined at enrollment with the use of a standardized, self-administered questionnaire.

Patients were stratified on the basis of the tumor site (larynx vs. other), nodal stage (N0 vs. N1, N2a, or N2b vs. N2c or N3), and Zubrod's performance status score ( 0 vs. 1 ) and were randomly assigned to receive high-dose cisplatin concurrently with either accelerated-fractionation radiotherapy (with the acceleration provided by means of concomitant boost radiotherapy) or standardfractionation radiotherapy. The accelerated-fractionation radiotherapy consisted of the delivery of 72 Gy in 42 fractions over a 6-week period, with a concomitant boost of twice-daily irradiation for 12 treatment days (as previously reported ${ }^{9}$ ), and standard-fractionation radiotherapy consisted of the delivery of $70 \mathrm{~Gy}$ in 35 fractions (i.e., $2 \mathrm{~Gy}$ per fraction) over a 7-week period. Intravenous cisplatin was administered at a dose of $100 \mathrm{mg}$ per square meter of body-surface area on days 1 and 22 in the accelerated-fractionation radiotherapy group and on days 1, 22, and 43 in the standardfractionation radiotherapy group.

Acute toxicity was evaluated weekly during the period of therapy according to the Common Terminology Criteria, version 2.0 (http://ctep .info.nih.gov/protocolDevelopment/electronic_ applications/docs/ctcv20_4-30-992.pdf). To assess tumor status and late toxicity, according to RTOG criteria, ${ }^{10}$ physical examinations and imaging studies were performed every 3 months for the first 2 years, every 6 months during years 3 through 5 , and annually thereafter.

\section{LABORATORY STUDIES}

The analysis of tumor HPV status was restricted to patients with oropharyngeal squamous-cell carcinoma because of the low prevalence of HPV among nonoropharyngeal squamous-cell carcinomas. ${ }^{1}$ This post hoc subgroup analysis was not 
part of the study protocol. Formalin-fixed, paraffin-embedded tumor specimens were evaluated for HPV-16 DNA with the use of the in situ hybridization-catalyzed signal-amplification method for biotinylated probes (GenPoint, Dako). ${ }^{11} \mathrm{HPV}-16-$ negative tumors were further evaluated for 12 additional oncogenic HPV types (18, 31, 33, 35, 39, 45, $51,52,56,58,59$, and 68 ) by means of a biotinylated-probe cocktail (GenPoint HPV Probe Cocktail, Dako). An HPV-positive tumor was defined as a tumor for which there was specific staining of tumor-cell nuclei for HPV in either analysis.

Tumor 16 expression was evaluated by means of immunohistochemical analysis with a mouse monoclonal antibody (MTM Laboratories) visualized with use of an autostainer (Ventana XT, Ventana) and a one-view secondary detection kit (Ventana). ${ }^{12}$ Positive p16 expression was defined as strong and diffuse nuclear and cytoplasmic staining in $70 \%$ or more of the tumor cells. ${ }^{12}$

\section{STUDY END POINTS}

The primary end point was overall survival, defined as the time from randomization to death. Secondary end points included progression-free survival, defined as the time from randomization to death or the first documented relapse, which was categorized as local-regional disease (tumor at the primary site or regional nodes) or distant metastases. Death from the primary cancer without a documented site of recurrence or death from an unknown cause was considered death from localregional disease. Second primary tumors were evaluated separately. Progression-free survival and its components (local-regional disease and distant metastases) were reported instead of protocolspecified secondary end points (e.g., disease-free survival) to facilitate comparison with published meta-analyses. ${ }^{13}$

\section{STATISTICAL ANALYSIS}

With a sample of 720 patients, the RTOG 0129 study had $80 \%$ statistical power to detect a relative reduction of $25 \%$ in the rate of death in the accelerated-fractionation radiotherapy group as compared with the standard-fractionation radiotherapy group, assuming a 2-year rate of overall survival of $45 \%$ in the standard-fractionation radiotherapy group, ${ }^{14,15}$ with the use of a one-sided test at the 0.05 significance level.

Rates of overall survival and progression-free survival were estimated by means of the KaplanMeier method and were compared between the two groups with the use of the log-rank test. The cumulative incidence method and Gray's test were used to estimate and compare rates of localregional relapse, distant metastases, and second primary tumors.

Cox proportional-hazards models were used to estimate hazard ratios; multivariable models were developed by minimizing Akaike's information criterion. Cox regression was performed with the use of data on tumor HPV status and smoking status, for patients for whom these data were available. Unadjusted and adjusted hazard ratios for HPV-positive and HPV-negative status were compared between the two groups to estimate the proportion of the difference in survival that was attributable to covariates. To investigate potential bias in estimates due to missing data on HPV status, we repeated the analyses for the subgroup of patients with oropharyngeal squamouscell carcinoma and for the entire RTOG study cohort (assuming the nonoropharyngeal squamous-cell carcinoma tumors were HPV-negative), using values imputed with the Markov chain Monte Carlo algorithm with a noninformative prior distribution (SAS/STAT software, with SAS OnlineDoc 9.1.3; SAS Institute). Twenty data sets were created, and the resulting analyses were combined per Rubin's formula. ${ }^{16}$ Recursive-partitioning analysis (for censored survival data) was performed with the use of S-Tree software (http:/l peace.med.yale.edu/pub/stree) to identify the factors that were most influential for overall survival and to permit the classification of patients with oropharyngeal squamous-cell carcinoma as having a low, intermediate, or high risk of death. ${ }^{17}$

\section{RESULTS}

\section{CHARACTERISTICS OF THE PATIENTS}

From July 2002 through May 2005, a total of 743 patients were enrolled in the RTOG 0129 study and randomly assigned to receive accelerated-fractionation radiotherapy or standard-fractionation radiotherapy. Analyses were restricted to the 721 patients who met the protocol study criteria (360 patients in the accelerated-fractionation radiotherapy group and the 361 patients in the standardfractionation radiotherapy group); of the remaining 22 patients, 17 were found to be ineligible and 5 withdrew consent. The baseline characteristics of the two groups are listed in Table 1.

The majority of enrolled patients $(60.1 \%$ [ 433 of 721]) had oropharyngeal squamous-cell carci- 
noma, and HPV status was determined in $74.6 \%$ of these patients (323 of 433). Tumor specimens were not available for study in 94 patients, and tissue specimens from 16 patients did not contain tumor tissue. No significant differences in baseline characteristics, overall survival, or progression-free survival were found between patients in whom HPV status was determined and those in whom it was not, arguing against significant selection bias (see the Supplementary Appendix, available with the full text of this article at NEJM .org). HPV DNA was detected in $63.8 \%$ of patients' tumors (206 of the 323) by means of in situ hybridization, and $96.1 \%$ of the samples (198 of 206) were positive for HPV-16.

HPV-positive oropharyngeal cancer was more common among patients who had never smoked and those with a lower number of cumulative pack-years of tobacco smoking than among those with a history of heavier smoking and was also significantly associated with several favorable prognostic factors, including younger age, white race, better performance status, absence of anemia, and smaller primary tumors (Table 1). The two treatment groups were balanced with regard to tumor HPV status.

\section{SURVIVAL AND TOXICITY}

There were no significant differences between the accelerated-fractionation radiotherapy group and the standard-fractionation radiotherapy group with regard to the rate of death within 30 days after the start of therapy (3.3\% and $1.9 \%$, respectively; $\mathrm{P}=0.26$ ) or the overall rates of grade 3 or 4 acute toxic events $(80.0 \%$ and $83.7 \%$, respectively; $\mathrm{P}=0.21)$ and late toxic events $(25.7 \%$ and $21.1 \%$, respectively; $\mathrm{P}=0.18$ ). At the data cutoff point (August 2009), 418 patients were alive. After a median follow-up of 4.8 years (range, 0.3 to 6.5 ), there was no significant difference in the 3-year rate of overall survival between the acceleratedfractionation radiotherapy group $(70.3 \%$; $95 \%$ confidence interval [CI], 65.6 to 75.1 ) and the standardfractionation radiotherapy group $(64.3 \%$; $95 \% \mathrm{CI}$, 59.3 to $69.2 ; \mathrm{P}=0.18$ ). There was a nonsignificant reduction of $10 \%$ in the risk of death for the accelerated-fractionation radiotherapy group as compared with the standard-fractionation radiotherapy group (hazard ratio, $0.90 ; 95 \% \mathrm{CI}, 0.72$ to 1.13), with a similar reduction in the subgroup of patients with HPV-positive cancer $(11 \%$; hazard ratio, $0.89 ; 95 \%$ CI, 0.51 to 1.55 ) and in the subgroup with HPV-negative cancer (9\%; hazard ratio, 0.91;
$95 \%$ CI, 0.69 to 1.19). The accelerated-fractionation radiotherapy group and the standard-fractionation radiotherapy group did not differ significantly with regard to progression-free survival or the pattern of relapse (see the Supplementary Appendix).

\section{HPV STATUS AND SURVIVAL}

For analysis of the association of tumor HPV status with survival, we combined the data for all patients with oropharyngeal squamous-cell carcinoma, since the survival rates were similar in the two treatment groups. In a Kaplan-Meier analysis, patients with HPV-positive cancer had better overall survival and progression-free survival than patients with HPV-negative cancer $(\mathrm{P}<0.001$ for both end points, by the log-rank test). The 3-year rates of overall survival were $82.4 \%$ (95\% CI, 77.2 to 87.6 ) in the HPV-positive subgroup and 57.1\% (95\% CI, 48.1 to 66.1) in the HPV-negative subgroup (Fig. $1 \mathrm{~A})$, and the 3-year rates of progression-free survival were $73.7 \%$ (95\% CI, 67.7 to 79.8 ) and $43.4 \%$ (95\% CI, 34.4 to 52.4), respectively (Fig. 1B).

In the multivariable analysis, age, race, performance status, tumor stage, nodal stage, and number of pack-years of tobacco smoking were also significant determinants of overall survival and progression-free survival (Table 2). By comparing the unadjusted hazard ratios for HPV-positive versus HPV-negative tumor status (hazard ratio for death, 0.38 ; $95 \%$ CI, 0.26 to 0.55 ; and hazard ratio for relapse or death, $0.40 ; 95 \%$ CI, 0.29 to 0.57 ) (Fig. 1A and $1 \mathrm{~B}$ ) with the corresponding adjusted hazard ratios (provided below), we estimated that these factors accounted for a relative difference of approximately $9 \%$ in the rates of overall survival and progression-free survival between patients with HPV-positive and those with HPV-negative oropharyngeal squamous-cell carcinoma. Nonetheless, after this adjustment, patients with HPV-positive tumors had a 58\% reduction in the risk of death as compared with patients with HPV-negative tumors (hazard ratio, 0.42; 95\% CI, 0.27 to 0.66 ) and a $51 \%$ reduction in the risk of relapse or death (hazard ratio, 0.49; 95\% CI, 0.33 to 0.74 ) (Table 2). After imputation for missing data, the results were similar (Table 2).

Tumors were evaluated for the expression of not only HPV but also a known biomarker of HPVoncoprotein function, the cyclin-dependent-kinase inhibitor p16, which is induced as a consequence of $\mathrm{pRb}$ inactivation by the HPV E7 oncoprotein ${ }^{18}$ but is minimally detectable in HPV-negative tumors because of epigenetic or genetic silencing. ${ }^{19}$ 
The presence of HPV DNA and the presence of p16 expression in tumors had very good agreement (kappa $=0.80 ; 95 \% \mathrm{CI}, 0.73$ to 0.87 ). Using p16 expression as a stratification factor, we found differences in overall and progression-free survival that were consistent with those based on HPV status. In unadjusted analyses, the 3-year rate of overall survival was $83.6 \%$ (95\% CI, 78.7 to 88.6 ) in the subgroup that was positive for p16 expression and $51.3 \%$ (95\% CI, 41.5 to 61.0$)$ in the subgroup that was negative for $\mathrm{p} 16$ expression (haz- ard ratio for death with positive p16 expression, 0.29; 95\% CI, 0.20 to 0.43 ) (Fig. 1C); the 3-year rate of progression-free survival was $74.4 \%(95 \% \mathrm{CI}$, 68.5 to 80.2 ) and $38.4 \%$ (95\% CI, 28.9 to 47.9 ), respectively (hazard ratio for relapse or death with positive p16 expression, 0.33 ; $95 \% \mathrm{CI}, 0.24$ to 0.46 ) (Fig. 1D). After adjustment for other factors, the corresponding hazard ratio for death was 0.33 ( $95 \%$ CI, 0.21 to 0.53 ), and the corresponding hazard ratio for relapse or death was $0.42(95 \% \mathrm{CI}$, 0.28 to 0.64$)$.

\begin{tabular}{|c|c|c|c|c|c|}
\hline \multirow[t]{2}{*}{ Characteristic } & \multicolumn{2}{|c|}{ All Study Patients } & \multicolumn{3}{|c|}{$\begin{array}{l}\text { Patients with Oropharyngeal Cancer } \\
\text { and Known Tumor HPV Status }\end{array}$} \\
\hline & $\begin{array}{c}\text { Standard- } \\
\text { Fractionation } \\
\text { Radiotherapy and } \\
\text { Cisplatin }(\mathrm{N}=361)\end{array}$ & $\begin{array}{c}\text { Accelerated- } \\
\text { Fractionation } \\
\text { Radiotherapy and } \\
\text { Cisplatin }(\mathrm{N}=360)\end{array}$ & $\begin{array}{l}\text { HPV-Positive } \\
\qquad(\mathrm{N}=206)\end{array}$ & $\begin{array}{l}\text { HPV-Negative } \\
\qquad(\mathrm{N}=117)\end{array}$ & P Value \\
\hline Treatment assignment — no. (\%) & & & & & 0.86 \\
\hline $\begin{array}{l}\text { Standard-fractionation radiotherapy } \\
\text { and cisplatin }\end{array}$ & $361(100)$ & 0 & $106(51.5)$ & $59(50.4)$ & \\
\hline $\begin{array}{l}\text { Accelerated-fractionation radiotherapy } \\
\text { and cisplatin }\end{array}$ & 0 & $360(100)$ & $100(48.5)$ & $58(49.6)$ & \\
\hline Age $-y r$ & & & & & 0.02 \\
\hline Median & 56.0 & 55.0 & 53.5 & 57.0 & \\
\hline Range & $34-82$ & $26-82$ & $31-78$ & $37-82$ & \\
\hline Sex - no. (\%) & & & & & 0.10 \\
\hline Male & $309(85.6)$ & $288(80.0)$ & $178(86.4)$ & $93(79.5)$ & \\
\hline Female & $52(14.4)$ & $72(20.0)$ & $28(13.6)$ & $24(20.5)$ & \\
\hline Race - no. $(\%) \ddagger$ & & & & & $<0.001$ \\
\hline White & $290(80.3)$ & $299(83.1)$ & $190(92.2)$ & $88(75.2)$ & \\
\hline Nonwhite & $71(19.7)$ & $61(16.9)$ & $16(7.8)$ & $29(24.8)$ & \\
\hline Zubrod's performance status score - no. (\%)』 & & & & & 0.03 \\
\hline 0 & $206(57.1)$ & $211(58.6)$ & $141(68.4)$ & $66(56.4)$ & \\
\hline 1 & $155(42.9)$ & $149(41.4)$ & $65(31.6)$ & $51(43.6)$ & \\
\hline Anemia - no. (\%)ף & & & & & 0.006 \\
\hline No & $250(69.3)$ & $247(68.6)$ & $161(78.2)$ & $75(64.1)$ & \\
\hline Yes & $111(30.7)$ & $113(31.4)$ & $45(21.8)$ & $42(35.9)$ & \\
\hline \multicolumn{6}{|l|}{ Primary site - no. (\%) } \\
\hline Oral cavity & $24(6.6)$ & $18(5.0)$ & 0 & 0 & \\
\hline Oropharynx & $216(59.8)$ & $217(60.3)$ & $206(100)$ & $117(100)$ & \\
\hline Hypopharynx & $31(8.6)$ & $27(7.5)$ & 0 & 0 & \\
\hline Larynx & $90(24.9)$ & $98(27.2)$ & 0 & 0 & \\
\hline Tumor stage — no. (\%) & & & & & 0.006 \\
\hline $\mathrm{T} 2$ & 69 (19.1) & $99(27.5)$ & $71(34.5)$ & $28(23.9)$ & \\
\hline $\mathrm{T} 3$ & $169(46.8)$ & $159(44.2)$ & $84(40.8)$ & $43(36.8)$ & \\
\hline $\mathrm{T} 4$ & $123(34.1)$ & $102(28.3)$ & $51(24.8)$ & $46(39.3)$ & \\
\hline
\end{tabular}




\begin{tabular}{|c|c|c|c|c|c|}
\hline \multirow[t]{2}{*}{ Characteristic } & \multicolumn{2}{|c|}{ All Study Patients } & \multicolumn{3}{|c|}{$\begin{array}{l}\text { Patients with Oropharyngeal Cancer } \\
\text { and Known Tumor HPV Status }\end{array}$} \\
\hline & $\begin{array}{c}\text { Standard- } \\
\text { Fractionation } \\
\text { Radiotherapy and } \\
\text { Cisplatin }(\mathrm{N}=361)\end{array}$ & $\begin{array}{c}\text { Accelerated- } \\
\text { Fractionation } \\
\text { Radiotherapy and } \\
\text { Cisplatin }(\mathrm{N}=360)\end{array}$ & $\begin{array}{l}\text { HPV-Positive } \\
(\mathrm{N}=206)\end{array}$ & $\begin{array}{l}\text { HPV-Negative } \\
\quad(\mathrm{N}=117)\end{array}$ & P Value $\dagger$ \\
\hline Nodal stage - no. (\%) & & & & & 0.46 \\
\hline No & $67(18.6)$ & $69(19.2)$ & $15(7.3)$ & $9(7.7)$ & \\
\hline $\mathrm{N} 1$ & $54(15.0)$ & $53(14.7)$ & $22(10.7)$ & $24(20.5)$ & \\
\hline $\mathrm{N} 2 \mathrm{a}$ & $28(7.8)$ & $32(8.9)$ & $25(12.1)$ & $12(10.3)$ & \\
\hline $\mathrm{N} 2 \mathrm{~b}$ & $94(26.0)$ & $95(26.4)$ & $78(37.9)$ & $29(24.8)$ & \\
\hline $\mathrm{N} 2 \mathrm{c}$ & $89(24.7)$ & $84(23.3)$ & $44(21.4)$ & $34(29.1)$ & \\
\hline N3 & $29(8.0)$ & $27(7.5)$ & $22(10.7)$ & $9(7.7)$ & \\
\hline AJCC stage - no. (\%) & & & & & 0.30 \\
\hline III & $77(21.3)$ & $81(22.5)$ & $25(12.1)$ & $19(16.2)$ & \\
\hline IV & $284(78.7)$ & $279(77.5)$ & 181 (87.9) & $98(83.8)$ & \\
\hline Tobacco exposure - no. (\%) & & & & & $<0.001$ \\
\hline Never smoked & $44(12.2)$ & 69 (19.2) & $59(28.6)$ & $14(12.0)$ & \\
\hline Former smoker & $191(52.9)$ & $183(50.8)$ & $110(53.4)$ & $54(46.2)$ & \\
\hline Current smoker & $83(23.0)$ & $68(18.9)$ & $24(11.7)$ & $32(27.4)$ & \\
\hline Unknown & $43(11.9)$ & $40(11.1)$ & $13(6.3)$ & $17(14.5)$ & \\
\hline Tobacco-smoking history — no. of pack-years $\|$ & & & & & $<0.001$ \\
\hline Median & 33 & 24 & 12.2 & 36.5 & \\
\hline Range & $0-137.5$ & $0-152.0$ & $0-152.0$ & 0-96.0 & \\
\hline \multicolumn{6}{|l|}{$\begin{array}{l}\text { HPV status of primary oropharyngeal tumor } \\
\qquad \text { no./total no. (\%) }\end{array}$} \\
\hline Positive & $106 / 216(49.1)$ & $100 / 217(46.1)$ & $206 / 206(100)$ & 0 & \\
\hline Negative & $59 / 216(27.3)$ & $58 / 217(26.7)$ & 0 & $117 / 117(100)$ & \\
\hline Unknown & $51 / 216(23.6)$ & $59 / 217(27.2)$ & 0 & 0 & \\
\hline $\begin{array}{l}\text { pl6 Expression in oropharyngeal primary } \\
\text { tumor - no./total no. (\%) }\end{array}$ & & & & & $<0.001$ \\
\hline Positive & $114 / 216(52.8)$ & $101 / 217(46.5)$ & $192 / 206(93.2)$ & $22 / 117(18.8)$ & \\
\hline Negative & $48 / 216(22.2)$ & $53 / 217(24.4)$ & $7 / 206(3.4)$ & $94 / 117(80.3)$ & \\
\hline Unknown & $54 / 216(25.0)$ & $63 / 217(29.0)$ & $7 / 206(3.4)$ & $1 / 117(0.9)$ & \\
\hline
\end{tabular}

* AJCC denotes the American Joint Committee on Cancer, and HPV human papillomavirus.

$\dagger P$ values were calculated with the use of Pearson's chi-square test for all comparisons, except age and pack-years, for which the KolmogorovSmirnov test was used, and tumor stage and nodal stage, for which the Kruskal-Wallis test was used.

$\leftarrow$ Race was self-reported.

$\int$ Zubrod's performance status scores of 0 and 1 correspond to asymptomatic performance and symptomatic but ambulatory performance, respectively.

I Anemia was defined as a hemoglobin level of $13.5 \mathrm{~g}$ per deciliter or less for men and $12.5 \mathrm{~g}$ per deciliter or less for women.

$\|$ A pack-year is defined as the equivalent of smoking one pack of cigarettes per day for 1 year. Data on pack-years were missing for 28 of the 206 patients (13.6\%) with HPV-positive tumors and 29 of the 117 patients (24.8\%) with HPV-negative tumors.

Tobacco smoking was also independently associated with overall survival and progression-free survival both in the subgroup of patients with oropharyngeal squamous-cell carcinoma and in the entire study population (Table 2). The risks of death and cancer relapse or death significantly increased by $1 \%$ for each additional pack-year of tobacco smoking (Table 2), and the magnitude of 


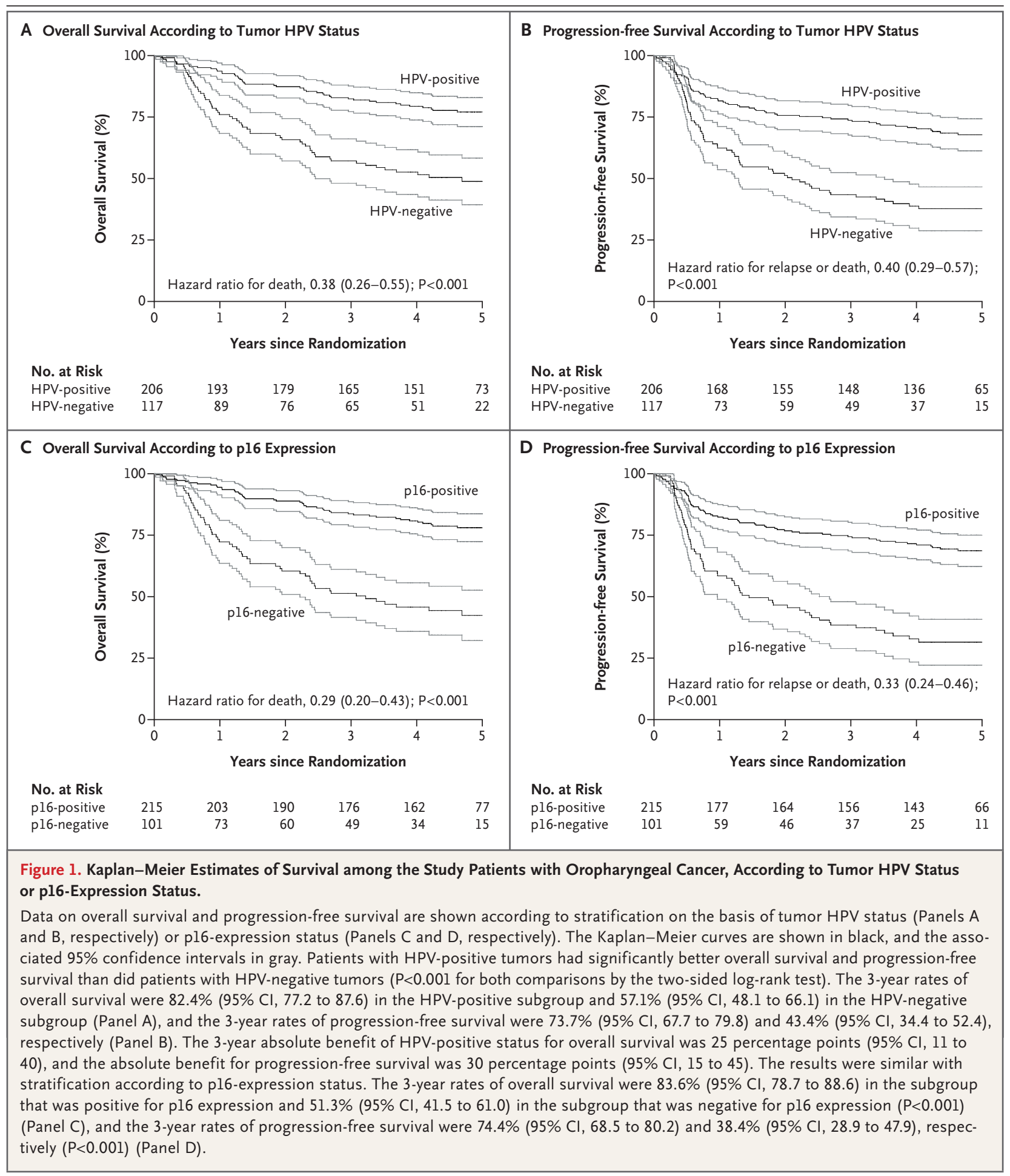

the tobacco effect was similar for patients with HPV-positive cancer (hazard ratio, 1.01; 95\% CI, 1.00 to 1.02) and those with HPV-negative cancer (hazard ratio, 1.01; 95\% CI, 1.00 to 1.03 ).
In an analysis of patterns of treatment failure among patients with oropharyngeal squamous-cell carcinoma, the 3-year rate of local-regional disease, but not distant metastasis, was significantly 


\begin{tabular}{|c|c|c|c|c|c|c|}
\hline \multirow[t]{3}{*}{ Covariate } & \multicolumn{4}{|c|}{ Patients with Oropharyngeal Cancer } & \multicolumn{2}{|c|}{$\begin{array}{l}\text { All Patients, with Data } \\
\text { Imputed }(\mathrm{N}=721)\end{array}$} \\
\hline & \multicolumn{2}{|c|}{ Complete Data $(\mathrm{N}=266)$} & \multicolumn{2}{|c|}{ Data Imputed ( $\mathrm{N}=433)$} & \multirow[b]{2}{*}{$\begin{array}{l}\text { hazard ratio } \\
(95 \% \mathrm{Cl})\end{array}$} & \multirow[b]{2}{*}{ Pvalue } \\
\hline & $\begin{array}{l}\text { hazard ratio } \\
(95 \% \mathrm{Cl})\end{array}$ & Pvalue & $\begin{array}{l}\text { hazard ratio } \\
(95 \% \mathrm{CI})\end{array}$ & Pvalue & & \\
\hline \multicolumn{7}{|l|}{ Overall survival } \\
\hline $\begin{array}{l}\text { Treatment assignment (accelerated- vs. standard- } \\
\text { fractionation radiotherapy) }\end{array}$ & $1.24(0.81-1.89)$ & 0.32 & $1.09(0.78-1.52)$ & 0.61 & $0.98(0.78-1.23)$ & 0.87 \\
\hline Age $(>50$ yr vs. $\leq 50$ yr) & $1.62(0.96-2.74)$ & 0.07 & $1.69(1.12-2.56)$ & 0.01 & $1.35(1.02-1.80)$ & 0.03 \\
\hline Race (nonwhite vs. white) & $1.57(0.89-2.75)$ & 0.12 & $2.13(1.39-3.25)$ & $<0.001$ & $1.56(1.18-2.05)$ & 0.002 \\
\hline Tumor stage (T4 vs. T2-T3) & $2.15(1.40-3.29)$ & $<0.001$ & $2.00(1.43-2.80)$ & $<0.001$ & $1.85(1.46-2.34)$ & $<0.001$ \\
\hline Nodal stage (N2b-N3 vs. N0-N2a) & $1.99(1.24-3.21)$ & 0.005 & $1.91(1.30-2.79)$ & $<0.001$ & $1.68(1.33-2.14)$ & $<0.001$ \\
\hline Pack-years of smoking (per increase of 1 yr) & $1.01(1.00-1.02)$ & 0.003 & $1.01(1.01-1.02)$ & $<0.001$ & $1.01(1.00-1.01)$ & 0.002 \\
\hline HPV status (positive vs. negative) & $0.42(0.27-0.66)$ & $<0.001$ & $0.50(0.33-0.76)$ & 0.002 & $0.41(0.29-0.57)$ & $<0.001$ \\
\hline HPV status (negative vs. positive) & $2.38(1.51-3.74)$ & $<0.001$ & $2.00(1.31-3.06)$ & 0.002 & $2.44(1.75-3.41)$ & $<0.001$ \\
\hline \multicolumn{7}{|l|}{ Progression-free survival } \\
\hline $\begin{array}{l}\text { Treatment assignment (accelerated- vs. standard- } \\
\text { fractionation radiotherapy) }\end{array}$ & $1.19(0.81-1.73)$ & 0.38 & $1.12(0.83-1.50)$ & 0.46 & $1.06(0.86-1.31)$ & 0.58 \\
\hline Age $(>50$ yr vs. $\leq 50 \mathrm{yr})$ & $1.69(1.05-2.72)$ & 0.03 & $1.73(1.20-2.50)$ & 0.003 & $1.39(1.08-1.80)$ & 0.01 \\
\hline Race (nonwhite vs. white) & $1.43(0.85-2.39)$ & 0.18 & $1.66(1.13-2.44)$ & 0.01 & $1.41(1.09-1.82)$ & 0.009 \\
\hline Zubrod's performance status score ( 1 vs. 0 ) & $1.42(0.97-2.09)$ & 0.07 & $1.44(1.05-1.96)$ & 0.02 & $1.51(1.22-1.88)$ & $<0.001$ \\
\hline Tumor stage (T4 vs. T2-T3) & $1.48(1.00-2.20)$ & 0.05 & $1.32(0.96-1.80)$ & 0.08 & $1.43(1.15-1.78)$ & 0.001 \\
\hline Nodal stage (N2b-N3 vs. N0-N2a) & $1.60(1.06-2.42)$ & 0.03 & $1.51(1.09-2.10)$ & 0.01 & $1.54(1.24-1.91)$ & $<0.001$ \\
\hline Pack-years of smoking (per increase of $1 \mathrm{yr}$ ) & $1.01(1.00-1.02)$ & 0.002 & $1.01(1.00-1.01)$ & 0.002 & $1.01(1.00-1.01)$ & 0.002 \\
\hline HPV status (positive vs. negative) & $0.49(0.33-0.74)$ & $<0.001$ & $0.53(0.37-0.76)$ & $<0.001$ & $0.48(0.36-0.65)$ & $<0.001$ \\
\hline HPV status (negative vs. positive) & $2.02(1.35-3.03)$ & $<0.001$ & $1.88(1.31-2.70)$ & $<0.001$ & $2.06(1.55-2.75)$ & $<0.001$ \\
\hline $\begin{array}{l}\text { HPV denotes human papillomavirus. Estimates fo } \\
\text { puted (with the use of } 20 \text { imputations) were data } \\
\text { tients with primary oropharyngeal cancer. Patients } \\
\text { Missing number of pack-years was imputed for a t } \\
\text { ratio for death among patients with HPV-negative } \\
(100 \times[1-2.38 \div 2.62]) \text { of the different in survival b } \\
\text { model with complete data and up to } 25 \% \text { ( } 100 \times[1 \\
\text { HPV-positive oropharyngeal squamous-cell carcin } \\
\text { nonoropharyngeal squamous-cell carcinoma were } \\
\text { death ( } 2.02 \text { and } 2.09 \text {, respectively). }\end{array}$ & $\begin{array}{l}\text { with a nonorophar } \\
\text { otal of } 163 \text { patient } \\
\text { (vs. HPV-positive) } \\
\text { etween patients wit } \\
-2.00 \div 2.62] \text { ) in th } \\
\text { ma as the referen } \\
\text { associated with sin }\end{array}$ & $\begin{array}{l}\mathrm{s}, 80 \text { of w } \\
\text { tumors o } \\
\text { th HPV-p } \\
\text { e model } \\
\text { ce group, } \\
\text { nilar haza }\end{array}$ & $\begin{array}{l}\text { mary site were assu } \\
2.62 \text {, we estimated } \\
\text { itive tumors and th } \\
\text { h imputations. In } \\
\text { PV-negative oroph } \\
\text { ratios for death }\end{array}$ & $\begin{array}{l}\text { med to h } \\
\text { eal cance } \\
\text { that the c } \\
\text { lose with } \\
\text { model } \mathrm{w} \\
\text { aryngeal } \\
.29 \text { and } 2\end{array}$ & $\begin{array}{l}\text { was imputed for } \\
\text { HPV-negative tum } \\
\text { sing the unadjuste } \\
\text { riates could accou } \\
\text { V-negative tumors } \\
\text { data from all patie } \\
\text { amous-cell carcino } \\
\text {, respectively) and }\end{array}$ & $\begin{array}{l}\text { vere im- } \\
10 \text { pa- } \\
\text { ors. } \\
d \text { hazard } \\
\text { t for } 9 \% \\
\text { in the } \\
\text { nts, with } \\
\text { na and } \\
\text { relapse or }\end{array}$ \\
\hline
\end{tabular}

lower for patients with HPV-positive tumors than for those with HPV-negative tumors (13.6\% vs. $35.1 \%, \mathrm{P}<0.001$ ) (Table 3). In addition, the cumulative incidence of second primary tumors was significantly lower among patients with HPV-positive tumors, largely because of lower rates of smoking-related cancer (Table 3).

Recursive-partitioning analysis showed that the HPV status of the tumor was the major determinant of overall survival, followed by the number of pack-years of tobacco smoking ( $\leq 10$ vs. $>10$ ) and then nodal stage (N0 to N2a vs. N2b to N3), for HPV-positive tumors, or tumor stage (T2 or T3 vs. T4), for HPV-negative tumors (Fig. 2A). This analysis classified patients with oropharyngeal squamous-cell carcinoma into three categories with respect to the risk of death: low risk, with a 3-year rate of overall survival of $93.0 \%$; intermediate risk, with a 3-year rate of $70.8 \%$ (hazard ratio for the comparison with low risk, 3.54; 95\% CI, 1.91 to 6.57); and high risk, with a 3-year rate of $46.2 \%$ (hazard ratio for the comparison with low risk, 7.16; 95\% CI, 3.97 to 12.93) (Fig. 2B). Patients with HPV-positive tumors were considered to be 


\begin{tabular}{|c|c|c|c|}
\hline Variable & $\begin{array}{l}\text { HPV-Positive } \\
\qquad(\mathrm{N}=206)\end{array}$ & $\begin{array}{l}\text { HPV-Negative } \\
\quad(\mathrm{N}=117)\end{array}$ & P Value \\
\hline Overall survival at $3 \mathrm{yr}-\%(95 \% \mathrm{Cl})$ & $82.4(77.2-87.6)$ & $57.1(48.1-66.1)$ & $<0.001$ \\
\hline Cause of death - no. of patients/total no. (\%) & & & 0.67 \\
\hline Primary cancer & $25 / 50(50.0)$ & $29 / 58(50.0)$ & \\
\hline Second primary tumor & $4 / 50(8.0)$ & $8 / 58(13.8)$ & \\
\hline Protocol treatment & $1 / 50(2.0)$ & $0 / 58$ & \\
\hline Nonprotocol treatment & $1 / 50(2.0)$ & $1 / 58(1.7)$ & \\
\hline Cause unrelated to cancer or treatment & $10 / 50(20.0)$ & $8 / 58(13.8)$ & \\
\hline Unknown & $9 / 50(18.0)$ & $12 / 58(20.7)$ & \\
\hline Progression-free survival at $3 \mathrm{yr}-\%(95 \% \mathrm{Cl})$ & $73.7(67.7-79.8)$ & $43.4(34.4-52.4)$ & $<0.001$ \\
\hline Local-regional relapse at $3 \mathrm{yr}-\%(95 \% \mathrm{Cl})$ & $13.6(8.9-18.3)$ & $35.1(26.4-43.8)$ & $<0.001$ \\
\hline Distant metastasis at $3 \mathrm{yr}-\%(95 \% \mathrm{Cl})$ & $8.7(4.9-12.6)$ & $14.6(8.1-21.1)$ & 0.23 \\
\hline Type of first treatment failure - no. of patients/total no. (\%) & & & 0.55 \\
\hline Local-regional disease & $26 / 66(39.4)$ & $33 / 72(45.8)$ & \\
\hline Distant metastasis & $21 / 66(31.8)$ & $17 / 72(23.6)$ & \\
\hline Death, no documented progression & $19 / 66(28.8)$ & $22 / 72(30.6)$ & \\
\hline Second primary tumor at $3 \mathrm{yr}-\%(95 \% \mathrm{Cl})$ & $5.9(2.6-9.1)$ & $14.6(8.1-21.0)$ & 0.02 \\
\hline Site of second primary tumor - no. of patients/total no. (\%) & & & 0.91 \\
\hline Head and neck & $5 / 19(26.3)$ & $5 / 21(23.8)$ & \\
\hline Lung & $8 / 19(42.1)$ & $9 / 21(42.9)$ & \\
\hline Prostate & $2 / 19(10.5)$ & $2 / 21(9.5)$ & \\
\hline Colon & $0 / 19$ & $1 / 21(4.8)$ & \\
\hline Rectum & $0 / 19$ & $1 / 21(4.8)$ & \\
\hline Kidney & $0 / 19$ & $1 / 21(4.8)$ & \\
\hline Breast & $0 / 19$ & $1 / 21(4.8)$ & \\
\hline Skin & $3 / 19(15.8)$ & $1 / 21(4.8)$ & \\
\hline Unknown & $1 / 19(5.3)$ & $0 / 21$ & \\
\hline
\end{tabular}

* HPV denotes human papillomavirus.

$\dagger P$ values were calculated with the use of Gray's test, except for overall and progression-free survival, for which the logrank test was used, and cause of death, type of first treatment failure, and site of second primary tumor, for which Pearson's chi-square test was used. The P value for the cause of death was calculated with primary cancer, protocol treatment, and nonprotocol treatment combined. The $\mathrm{P}$ value for the site of a second primary tumor was calculated with head and neck cancer and lung cancer (both of which are considered to be related to smoking) combined.

at low risk, with the exception of smokers with a high nodal stage (i.e., N2b to N3), who were considered to be at intermediate risk; patients with HPV-negative tumors were considered to be at high risk, with the exception of nonsmokers with tumors of stage $\mathrm{T} 2$ or $\mathrm{T} 3$, who were considered to be at intermediate risk.

\section{DISCUSSION}

This study provides strong evidence that tumor HPV status is an independent prognostic factor for overall survival and progression-free survival among patients with oropharyngeal squamous-cell carcinomas, which is consistent with the hypothesis that HPV-positive and HPV-negative oropharyngeal squamous-cell carcinomas are distinct and have different causes, ${ }^{20}$ risk-factor profiles, ${ }^{1}$ and survival outcomes. On the basis of our data, we believe that future clinical trials should be designed specifically for patients with HPV-positive or HPV-negative squamous-cell carcinoma of the head and neck or patients who have been stratified according to HPV status. Moreover, addition- 
Figure 2. Classification of the Study Patients into Riskof-Death Categories and Kaplan-Meier Estimates of Overall Survival According to Those Categories.

Recursive-partitioning analysis was used to identify prognostic factors with the most influential predictive significance in a proportional-hazards model of overall survival and to classify patients into categories of low, intermediate, or high risk of death. The prognostic factors in the analysis were age, tumor stage, nodal stage, race, smoking status, HPV status, anemia status, performance status, treatment assignment, and sex. Panel A shows the resulting classifications. Panel B shows data for overall survival in the classified patients. The Kaplan-Meier curves are shown in black, and the associated $95 \%$ confidence intervals in gray. The 3 -year rates of overall survival were $93.0 \%(95 \% \mathrm{Cl}, 88.3$ to $97.7)$ in the low-risk group, $70.8 \%(95 \% \mathrm{Cl}, 60.7$ to $80.8)$ in the intermediate-risk group, and $46.2 \%(95 \%$ $\mathrm{Cl}, 34.7$ to 57.7 ) in the high-risk group. Hazard ratios for death among the 266 patients for whom the risk classification could be made on the basis of the recorded data and among all 433 patients with oropharyngeal cancer (after missing data on HPV status and number of pack-years were estimated with the use of statistical imputation) were as follows: $3.54(95 \% \mathrm{Cl}$, 1.91 to 6.57$)$ and $2.67(95 \% \mathrm{Cl}, 1.54$ to 4.62$)$, respectively, in the intermediate-risk group versus the lowrisk group; and $7.16(95 \% \mathrm{Cl}, 3.97$ to 12.93$)$ and 5.23 ( $95 \% \mathrm{Cl}, 3.14$ to 8.73 ), respectively, in the high-risk group versus the low-risk group.

al information could be gleaned from completed clinical trials, by means of reanalysis, to determine whether imbalances in tumor HPV status between treatment groups affected the outcomes and thus the therapeutic implications.

Our analysis of the association of HPV status with survival was performed in a clinical trial of locally advanced squamous-cell carcinoma of the head and neck that did not show a significant difference in overall survival between a concomitantboost accelerated-fractionation regimen of radiotherapy and a standard-fractionation regimen, combined with concurrent, high-dose cisplatin. Therefore, either regimen could serve as the comparison for a new therapy being investigated.

We observed strong agreement between tumor HPV status, as determined by in situ hybridization, and expression of $\mathrm{p} 16$, an established biomarker for the function of the HPV E7 oncoprotein. Our HPV-16 in situ hybridization assay has sensitivity for single viral copies, and a positive result is strongly correlated with expression of the HPV E6 and E7 oncogenes - the standard for defining a tumor as being associated with HPV. ${ }^{21,22}$ A limitation of our method is the unknown sen-

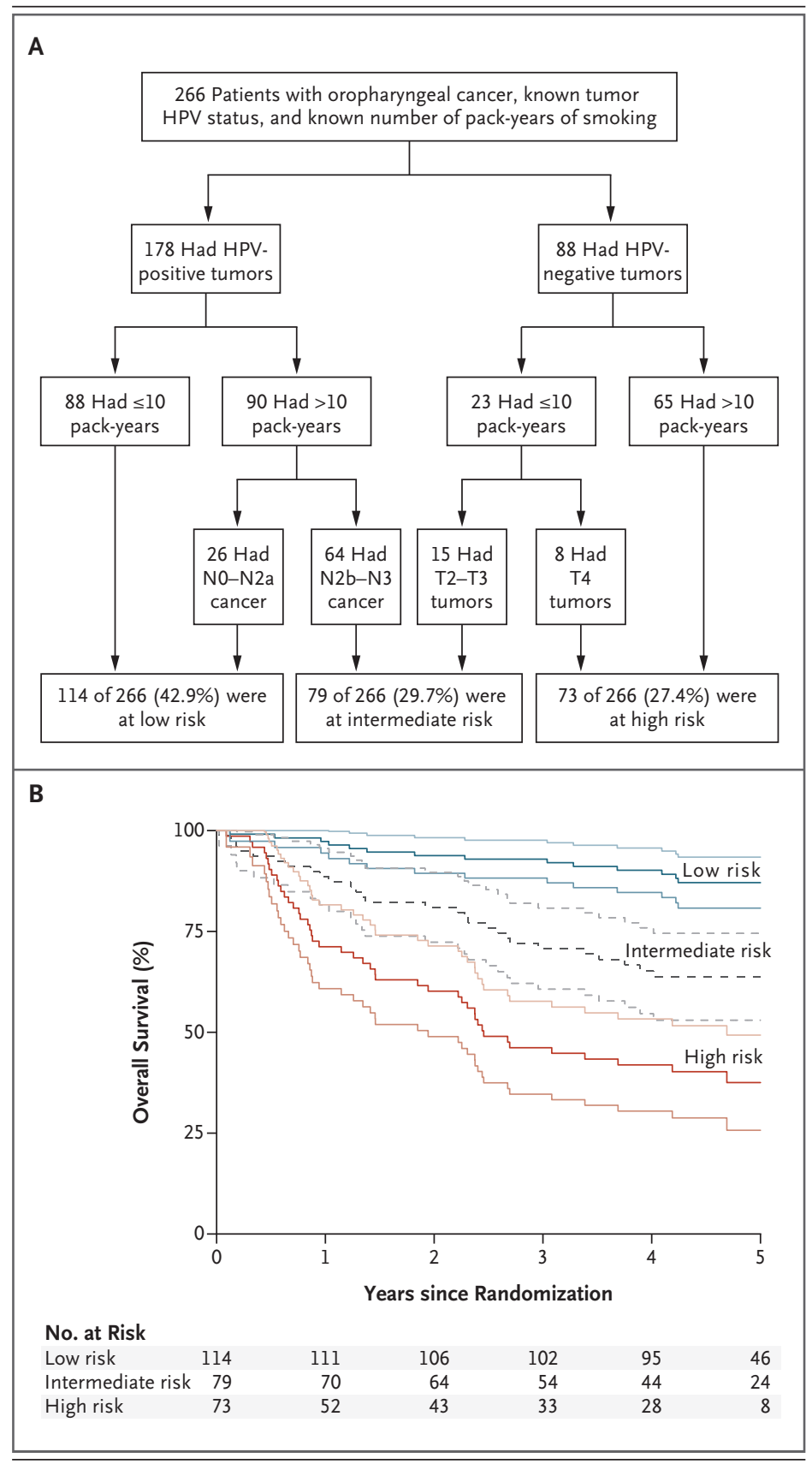

sitivity of the probe cocktail for non-HPV-16 types, which account for an estimated 5 to $10 \%$ of HPVpositive oropharyngeal squamous-cell carcinomas. ${ }^{23}$ Thus, the misclassification of HPV-positive tumors as HPV-negative tumors probably explains the slightly larger reduction in the risk of death when the analysis was based on status with respect to p16 expression rather than HPV presence. A strength of the p16-expression assay is that it is not specific for HPV type, unlike the in situ 
hybridization assays; therefore, p16-expression status is a very good surrogate for tumor HPV status.

The superior prognosis for HPV-positive oropharyngeal squamous-cell carcinoma, as compared with that for the HPV-negative cancer, appears to have multifactorial underpinnings. Known favorable prognostic factors associated with the HPV-positive subgroup account for approximately $10 \%$ of the detected difference in outcome. The higher survival rate among patients with HPVpositive cancer is due in part to greater localregional control, reflecting higher intrinsic sensitivity to radiation or better radiosensitization with the use of cisplatin. Although rates of response to induction chemotherapy are higher among patients with HPV-positive tumors than among those with HPV-negative tumors, ${ }^{4}$ single-agent cisplatin therapy did not appear to differentially affect the elimination of occult distant metastases. Second primary tumors, which are largely related to smoking, were less frequent among patients with HPVpositive tumors, a finding that is consistent with the lower exposure to tobacco in this subgroup. However, the rates of death from second primary tumors were similar in the HPV-positive and HPVnegative subgroups and therefore do not account for the overall differences in survival rates.

Our data clearly indicate that HPV status and status with respect to tobacco smoking are major independent prognostic factors for patients with oropharyngeal squamous-cell carcinoma, probably because they determine the molecular profile of the cancer and thus the response to therapy. Although HPV-positive oropharyngeal squamouscell carcinoma is genetically distinct from the HPV-negative cancer with respect to patterns of loss of heterozygosity, ${ }^{24}$ chromosomal abnormalities, ${ }^{25,26}$ and gene-expression profiles ${ }^{27}$ and is inversely correlated with biomarkers for a poor prognosis in squamous-cell carcinoma of the head and neck (e.g., p53 mutations ${ }^{28}$ or expression of epidermal growth factor receptor ${ }^{29}$ ), no specific mechanism has been shown to explain the higher rates of response to radiation therapy and chemotherapy among patients with HPV-positive cancer. ${ }^{4}$ Epidemiologic data indicate that tobacco smoking is not a strong cofactor for the development of HPV-positive oropharyngeal squamous-cell carcinoma. ${ }^{1}$ Nevertheless, our data reveal that the biologic behavior of an HPV-positive tumor may be altered by tobacco use. Genetic alterations in- duced by tobacco-associated carcinogens may render HPV-positive tumors less responsive to therapy. The likelihood of such genetic alterations appears to increase as the number of pack-years of tobacco smoking increases (Table 2). The cutoff point of 10 pack-years, which was the best predictor of survival in our recursive-partitioning analysis, may be more useful than a continuum for the design of future risk-based clinical trials but will require further validation.

The extent to which the superior survival for a patient with HPV-positive oropharyngeal squamouscell carcinoma depends on the administered therapy is unclear. Published data indicate that tumor HPV status is a strong and consistent determinant of superior survival, regardless of treatment strategy (e.g., surgery, ${ }^{30}$ radiation therapy, ${ }^{31,32}$ concurrent chemoradiation therapy [in this study], or induction chemotherapy plus concurrent chemoradiation therapy ${ }^{4,33}$ ), with 5 -year survival rates among patients with HPV-positive tumors of approximately 75 to $80 \%$, versus 45 to $50 \%$ among patients with HPV-negative tumors.

Though no direct evidence from formal clinical trials exists to guide treatment decisions for the individual patient on the basis of tumor HPV status, this study provides a direction for future clinical research. A combination of tumor HPV status, pack-years of tobacco smoking, and cancer stage may be used to classify patients as having a low, intermediate, or high risk of death. Whether patients with HPV-positive tumors who are considered to be in the low-risk category can be spared the long-term complications of intensive, multimodal therapy without compromising their survival is now a highly relevant clinical question. In contrast, such a strategy would be inappropriate for the $36 \%$ of patients with HPV-positive tumors who are in the intermediate-risk group, for whom the 3-year rate of overall survival ( $71 \%$, with an even lower rate of progression-free survival) is unacceptable. Unfortunately, patients in the highrisk group have an extremely poor prognosis and thus should be offered enrollment in trials testing more intensive investigational therapies. Should our risk model be validated in other cohorts, it will be important to incorporate tumor HPV status and tobacco exposure as nonanatomical determinants of risk classification and therapy selection for patients with oropharyngeal squamous-cell carcinoma. 
The contents of this article are the sole responsibility of the authors and do not necessarily represent the official views of the NCI or NIDCR.

Supported by grants (RTOG U10 CA21661, CCOP U10 CA37422, and P01 CA06294) from the National Cancer Institute (NCI), a grant (DE016631) from the National Institute of Dental and Craniofacial Research (NIDCR), and the Oral Cancer Foundation.

Disclosure forms provided by the authors are available with the full text of this article at NEJM.org.

\section{REFERENCES}

1. Gillison M, D'Souza G, Westra W, et al. Distinct risk factor profiles for human papillomavirus type 16-positive and human papillomavirus 16-negative head and neck cancers. J Natl Cancer Inst 2008; 100:407-20.

2. Rampias T, Sasaki C, Weinberger P, Psyrri A. E6 and E7 gene silencing and transformed phenotype of human papil lomavirus 16-positive oropharyngeal cancer cells. J Natl Cancer Inst 2009;101:412 23.

3. Ragin CC, Taioli E. Survival of squamous cell carcinoma of the head and neck in relation to human papillomavirus infection: review and meta-analysis. Int J Cancer 2007;121:1813-20.

4. Fakhry C, Westra WH, Li S, et al. Im proved survival of patients with human papillomavirus-positive head and neck squamous cell carcinoma in a prospective clinical trial. J Natl Cancer Inst 2008, 100:261-9.

5. Bourhis J, Overgaard J, Audry H, et al. Hyperfractionated or accelerated radiotherapy in head and neck cancer: a metaanalysis. Lancet 2006;368:843-54

6. Pignon J-P, le Maître A, Maillard E, Bourhis J. Meta-analysis of chemotherapy in head and neck cancer (MACH-NC): an update on 93 randomised trials and 17,346 patients. Radiother Oncol 2009;92 4-14.

7. Fleming I, Cooper J, Henson D, et al. eds. AJCC cancer staging manual. 5th ed. Philadelphia: Lippincott-Raven, 1997.

8. Oken MM, Creech RH, Tormey DC, et al. Toxicity and response criteria of the Eastern Cooperative Oncology Group. Am J Clin Oncol 1982;5:649-55.

9. Fu KK, Pajak TF, Trotti A, et al. A Ra diation Therapy Oncology Group (RTOG) phase III randomized study to compare hyperfractionation and two variants of accelerated fractionation to standard fractionation radiotherapy for head and neck squamous cell carcinomas: first report of RTOG 9003. Int J Radiat Oncol Biol Phys 2000;48:7-16.

10. Cox JD, Stetz J, Pajak TF. Toxicity criteria of the Radiation Therapy Oncology Group (RTOG) and the European Organization for Research and Treatment of Cancer (EORTC). Int J Radiat Oncol Biol Phys 1995;31:1341-6.

11. Huang CC, Qiu JT, Kashima ML, Kurman RJ, Wu TC. Generation of typespecific probes for the detection of single-copy human papillomavirus by a novel in situ hybridization method. Mod Pathol 1998;11:971-7.
12. Begum S, Gillison ML, Ansari-Lari MA, Shah K, Westra WH. Detection of human papillomavirus in cervical lymph nodes: a highly effective strategy for localizing site of tumor origin. Clin Cancer Res 2003;9:6469-75.

13. Michiels S, Le Maître A, Buyse M, et al. Surrogate endpoints for overall survival in locally advanced head and neck cancer: meta-analyses of individual patient data. Lancet Oncol 2009;10:341-50.

14. Marcial VA, Pajak TF, Mohiuddin M, et al. Concomitant cisplatin chemotherapy and radiotherapy in advanced mucosal squamous cell carcinoma of the head and neck: long-term results of the Radiation Therapy Oncology Group study 81-17. Cancer 1990;66:1861-8.

15. Adelstein DJ, Li Y, Adams GL, et al. An intergroup phase III comparison of standard radiation therapy and two schedules of concurrent chemoradiotherapy in patients with unresectable squamous cell head and neck cancer. J Clin Oncol 2003; 21:92-8.

16. Rubin D, ed. Multiple imputations for nonresponse in surveys. New York: Wiley, 1987.

17. Analysis of censored data: survival trees. In: Zhang H, Singer B. Recursive partitioning in the health sciences. New York: Springer-Verlag, 1999:93-104.

18. Nakao Y, Yang X, Yokoyama M, et al. Induction of p16 during immortalization by HPV16 and 18 and not during malignant transformation. Br J Cancer 1997;75: 1410-6.

19. Reed AL, Califano J, Cairns $\mathrm{P}$, et al. High frequency of p16 (CDKN2/MTS-1/ INK4A) inactivation in head and neck squamous cell carcinoma. Cancer Res 1996;56:3630-3.

20. Gillison ML, Koch WM, Capone RB, et al. Evidence for a causal association between human papillomavirus and a subset of head and neck cancers. J Natl Cancer Inst 2000;92:709-20.

21. Shi W, Kato H, Perez-Ordonez B, et al. Comparative prognostic value of HPV16 E6 mRNA compared with in-situ hybridization for human oropharyngeal squamous carcinoma. J Clin Oncol 2009;27:621321.

22. Smeets SJ, Hesselink AT, Speel EJ, et al. A novel algorithm for reliable detection of human papillomavirus in paraffin embedded head and neck cancer specimen. Int J Cancer 2007;121:2465-72.

23. Kreimer AR, Clifford GM, Boyle P, Franceschi S. Human papillomavirus types in head and neck squamous cell carcino- mas worldwide: a systematic review. Cancer Epidemiol Biomarkers Prev 2005;14: 467-75.

24. Braakhuis BJ, Snijders PJ, Keune WJ, et al. Genetic patterns in head and neck cancers that contain or lack transcriptionally active human papillomavirus. J Natl Cancer Inst 2004;96:998-1006.

25. Klussman J, Mooren J, Lehnen M, et al. Genetic signatures of HPV-related and unrelated oropharyngeal carcinoma and their prognostic implications. Clin Cancer Res 2009;15:1779-86.

26. Smeets SJ, Braakhuis BJ, Abbas S, et al. Genome-wide DNA copy number alterations in head and neck squamous cell carcinomas with or without oncogeneexpressing human papillomavirus. Oncogene 2006;25:2558-64.

27. Martinez I, Wang J, Hobson KF, Ferris RL, Khan SA. Identification of differentially expressed genes in HPV-positive and HPV-negative oropharyngeal squamous cell carcinomas. Eur J Cancer 2007;43:41532.

28. Westra WH, Taube JM, Poeta ML, Begum S, Sidransky D, Koch WM. Inverse relationship between human papillomavirus-16 infection and disruptive p53 gene mutations in squamous cell carcinoma of the head and neck. Clin Cancer Res 2008;14:366-9.

29. Kumar B, Cordell KG, Lee JS, et al. EGFR, p16, HPV titer, Bcl-xL and p53, sex, and smoking as indicators of response to therapy and survival in oropharyngeal cancer. J Clin Oncol 2008;26:3128-37.

30. Licitra L, Perrone F, Bossi P, et al. High-risk human papillomavirus affects prognosis in patients with surgically treated oropharyngeal squamous cell carcinoma. J Clin Oncol 2006;24:5630-6.

31. Lindquist D, Romanitan M, Hammarstedt L, et al. Human papillomavirus is a favourable prognostic factor in tonsillar cancer and its oncogenic role is supported by the expression of E6 and E7. Mol Oncol 2007;1:350-5.

32. Lassen P, Eriksen JG, Hamilton-Dutoit S, Tramm T, Alsner J, Overgaard J. Effect of HPV-associated p16INK4A expression on response to radiotherapy and survival in squamous cell carcinoma of the head and neck. J Clin Oncol 2009;27:1992-8.

33. Settle K, Posner MR, Schumaker LM, et al. Racial survival disparity in head and neck cancer results from low prevalence of human papillomavirus infection in black oropharyngeal cancer patients. Cancer Prev Res (Phila Pa) 2009;2:776-81.

Copyright (C) 2010 Massachusetts Medical Society. 